\title{
Estallido social, Covid-19 y educación: el caso del país que le tiene más miedo a un gobierno opresor que a un virus mortal
}

\section{Social outburst, Covid-19 and education: the case of the country that is more fear of an oppressive government than a mortal virus}

* Jonathan Cruz \& ** María Camila Castillo Cabezas

Cruz, J., \& Castillo, M. C. (2021). Estallido social, Covid-19 y educación: el caso del país que le tiene más miedo a un gobierno opresor que a un virus mortal Revista Convergencia Educativa, (10), diciembre, 78-90. https://doi.org/10.29035/rce.10.78

[Recibido: 06 octubre, 2021 / Aceptado: 27 octubre, 2021]

Cuando los justos gobiernan, el pueblo se alegra. Pero cuando los perversos están en el poder, el pueblo gime.

Proverbios 29:2 (NTV)

When the righteous are in authority, the people rejoice:

But when the wicked beareth rule, the people mourn.

Proverbs 29:2 (KJV)

\section{RESUMEN}

Este ensayo es una reflexión de un estudiante de universidad pública colombiana, donde se presentan análisis a lo acontecido al paro nacional, así como a los últimos 3 años en la política. El paro nacional colombiano ha sido objeto de múltiples respuestas, controversias, llamados y comparaciones. Aunque si bien esta sucesión de manifestaciones ha sacudido al país y ha atraído a extranjeros, se tiende a tomar la idea de que esto comenzó recién en el año 2019 pero, en realidad, viene de muchos más años atrás, particularmente del año pasado al 2019. Aunque el problema social y político puede provenir desde hace doscientos años, la realidad es que este estallido social tiene que ver con los últimos tres, en donde el ente político ha eclipsado a los entes sociales y económicos. Es por esto, entonces, que la ciudadanía colombiana ha emprendido el viaje de la transformación, a la expectativa de poderlo realizar. Se reconoce, también, que estas reflexiones no van de la línea con ningún partido político, sino que son solo meditaciones del autor.

Palabras clave: Gran Confinamiento, Paro Nacional, Colombia, Educación, Política.

* Técnico en mantenimiento de automotismo industriales. Candidato a grado licenciatura en Literatura. Universidad del Valle. Cali, Colombia. https://orcid.org/0000-0001-7821-4381 | cruz.jonathan@correounivalle.edu

** Magíster en Educación. Universidad del Valle. Cali, Colombia.

https://orcid.org/0000-0003-4086-9686 | maria.castillo.cabezas@correounivalle.edu.co 
Cruz, J., \& Castillo, M. C. (2021). Estallido social, Covid-19 y educación: el caso del país que le tiene más miedo a un gobierno opresor que a un virus mortal Revista Convergencia Educativa, (10), diciembre, 78-90. https://doi.org/10.29035/rce.10.78

\begin{abstract}
This essay is a reflection of a student of a Colombian public university, which presents an analysis of what happened on the national strike, as well as the last 3 years in politics. The Colombian national strike has been the object of multiple responses, controversies, appeals and comparisons. Although this succession of demonstrations has shaken the country and has attracted foreigners, there is a tendency to take the idea that this started only in 2019 but, in reality, it comes from many more years ago. Although the social and political problem may be two hundred years old, the reality is that this social outburst has to do with the last three, where the political organization has eclipsed the social and economic organizations. It is for this reason, then, that Colombian citizens have embarked on the journey of transformation, in the expectation of being able to achieve it. It is also recognized that these reflections are not in line with any political party, but only meditations of the author.
\end{abstract}

Key words: Great Confinement, National Strike, Colombia, Education, Politics.

\title{
INTRODUCCIÓN
}

Colombia siempre se ha situado entre los países más desiguales del mundo. Sin embargo, desde hace veinte años, con el arribo del uribismo, las cosas comenzarían a tornarse un poco más densas y turbias: grupos extralegales participando en apoyo militar a gobernantes, inseguridad nacional con el fin de mantener un caótico orden establecido, controlar las fuerzas del país en ámbitos sociales, jurídicos y económicos, así como generar ingresos privados para diferentes individuos públicos e impunidad para ellos. En los últimos tres años, con la vuelta al poder de ese mismo movimiento, se ha visibilizado la necesidad de un cambio en toda la estructura política, militar, social y económica del país. Particularmente desde estos dos últimos años, esa búsqueda está asociada a una inconformidad y desespero por parte de toda la región nacional. Es por este motivo que deseo presentar el estallido social de este año no como una gravante surgida gracias a la Reforma Tributaria presentada, ni al erróneo precio de una docena de huevos ${ }^{1}$, sino que es más el resultado de una olla a presión que se venía calentando desde que el señor Iván Duque Márquez llegó al poder, con el fin de realizar una suerte de línea temporal con los asuntos que comenzarían a aumentar la temperatura de esta olla. La llegada de Iván Duque, junto a su pésima administración y la particularidad histórica de la Gran Reclusión en la que nos encontramos, solo generaría motivaciones aún mayores para que las calles se llenaran de personas exigiendo un cambio que velara a favor del pueblo.

\footnotetext{
1 En una entrevista realizada por la periodista Vicky Dávila de la Revista Semana a Alberto Carrasquilla, el entonces ministro de hacienda, una de las preguntas fue acerca de la canasta familiar a la que, en la Reforma Tributaria que el mismo exministro presentó, le añadía impuestos, lo que subiría notablemente su precio. El exministro, sin embargo, anunció que la docena de huevos debería rondar los mil ochocientos pesos colombianos (COP \$1 800, más o menos 50 centavos de dólar), cuando en realidad su precio ronda los nueve mil pesos colombianos (alrededor de USD 2,50). Esto trajo mucha indignación a la ciudadanía colombiana, pues se preguntaban cómo era posible que alguien encargado de la política macroeconómica del país, no conozca, ni siquiera, el precio del mercado local. En algunas conversaciones, mis amistades han asociado los «huevos de Carrasquilla» con el alza a la tarifa del transporte público de Chile, ya que ambos fueron fuertes motivaciones para iniciar la búsqueda del cambio.
} 
Cruz, J., \& Castillo, M. C. (2021). Estallido social, Covid-19 y educación: el caso del país que le tiene más miedo a un gobierno opresor que a un virus mortal Revista Convergencia Educativa, (10), diciembre, 78-90. https://doi.org/10.29035/rce.10.78

Es por lo anterior que en este ensayo trataré, a manera de reflexión, el tema acerca de las acciones políticos, sociales y económicos desde una línea temporal, donde se presentarán cuatro años $(2018,2019$, 2020 y 2021), y en cada uno contaré diferentes instancias que apelarán al estallido social de 2021 como resultado. No sin antes aclarar que la molestia, el inconformismo y la problemática no viene de la posición de Iván Duque Márquez como presidente, sino que esta se arrastra desde hace casi veinte años, con el posicionamiento de su maestro y ahora jefe del partido al que pertenece gran parte del gobierno, Álvaro Uribe Vélez, como presidente de Colombia. Es decir, Iván Duque Márquez funge como la gota que rebasó un vaso que ya venía estando muy cargado.

En el primero de ellos, el cual me llama particularmente la atención que no he visto a nadie mencionarlo, se trata del primer paro estudiantil durante el mandato del presidente Iván Duque Márquez, que coincidía con el recién ascenso de este al poder. Se tratará el por qué comenzó la movilización, quiénes participaron, los motivos y en qué concluyó. Seguidamente, hablaré acerca de esa primavera colombiana del 2019, donde ya no solo se trataría de un movimiento o colectivo, o colectivos estudiantiles, sino que las movilizaciones comenzarían a ser masivas, además de que internacionalmente comenzaríamos a ser nombrados, pero todo esto sería interrumpido al siguiente año. Posteriormente, viene la etapa que nadie se esperaba: la Gran Reclusión o el Gran Confinamiento, siendo el segundo el elegido por el Fondo Monetario Internacional para referirse a toda la problemática que dejó la pandemia del Covid-19. Aquí mostraré datos que, si bien, no engendraron una nueva jornada de movilización en sus inicios, sí alimentó más el fuego con el que la olla estaba siendo calentada. Finalmente, me centraré en los meses de abril a agosto del 2021, para mostrarlo como el resultado de los anteriores, con lo que terminaré recogiendo todo lo informado y plantearía una posible culminación del periodo presidencial en el próximo año.

\section{El antecedente que nadie pronuncia}

Esto empezó así: en octubre del 2018, mismo año en el que el electo ganador, Iván Duque, hace poco se había colocado en el poder, algunos sectores mostrando su inconformidad (principalmente estudiantes y profesores; seguidos de indígenas, obreros y deportistas.) manifestándose o parando con la noticia del recorte de presupuestos a la salud, la educación, los deportes, las pensiones y la investigación para el año 2019. Para el apartado de la educación, Colombia tiene una deuda histórica con esta, especialmente después de la reforma a la Ley 30 (ley que velaba por el acceso de todo ciudadano colombiano a la educación pública, segura y gratuita), siendo lo más reciente el plan gubernamental de Ser Pilo Paga y el Instituto Colombiano de Crédito Educativo y Estudios Técnicos en el Exterior (ICETEX).

El presupuesto, que en teoría debía ser destinado a las Instituciones de Educación Superior (IES) públicas para infraestructura, mantenimiento y sostenimiento, en realidad se daba a unos créditos bancarios para aquellos aspirantes a estudiar en una universidad del país, se endeudaran con el Estado y, a lo largo de su vida fueran pagando la suma total del costo de su carrera, más unos intereses añadidos. Ahora bien, al ser un endeudamiento que te permite elegir cualquier tipo de universidad afiliada a los programas, los aspirantes, en su mayoría, han elegido universidades privadas. Esto de acuerdo con Moreno (2018), 
Cruz, J., \& Castillo, M. C. (2021). Estallido social, Covid-19 y educación: el caso del país que le tiene más miedo a un gobierno opresor que a un virus mortal Revista Convergencia Educativa, (10), diciembre, 78-90. https://doi.org/10.29035/rce.10.78

quiere decir que la mayoría de los recursos públicos para las universidades del Estado terminan dirigidos a universidades privadas, las cuales no dejan de aumentar su presupuesto cada año, gracias a estos dineros facilitados (Forbes Staff, 2020).

Por su parte, deportistas como Mariana Pajón, una de las deportistas nacionales más importantes e influyentes, se reunió con el presidente para pedir un no recorte al presupuesto nacional para el deporte. En una conferencia de prensa que dio la deportista, la revista Pulzo (2018) recogió: "que le suba el presupuesto al deporte, que no nos lo vaya a bajar, que tengamos un apoyo ahora con la carrera 2.1 (Colombia Oro y Paz), que nos dé presupuesto para esa carrera y que veamos que el deporte de verdad construye país"2. Así, también, los indígenas pidieron más atención a sus condiciones de vida, así como el respeto a los Acuerdos de Paz firmados por el expresidente Juan Manuel Santos con la guerrilla de las Fuerzas Armadas Revolucionarias de Colombia (FARC). De otro lado, los obreros y camioneros estaban luchando contra la Ley de Financiamiento, la reforma tributaria de ese año, que buscaba aumentar los impuestos.

Desde el 10 de octubre comenzaría, por fin, una huelga nacional estudiantil con un paro indefinido primero en las instituciones de mayor nombre en el país (Universidad Nacional, Universidad del Valle, Universidad Tecnológica de Pereira, Universidad de Caldas y la Universidad de Antioquia), reclamando más fondos del gobierno para financiar 32 universidades públicas.

"Se exige con urgencia que el mandatario pueda completar este año 4.500 millones de pesos, de los cuales 3.000 millones de pesos se destinarán a la educación superior pública, y los 1.5 pesos restantes se destinarán a tecnología e instituciones técnicas", dijo el estudiante líder Khristian León de la Universidad Nacional de Bogotá, la institución insignia del país (Moreno, 2018).

Fue en este mismo año en el que los profesores y estudiantes universitarios comenzaron a realizar el proceso de pedagogía local, explicando quién, por qué y para qué se protestaba, así como compartir espacios de conocimiento, debate y comunicación. Mis compañeros de la Licenciatura en Literatura de la Universidad del Valle (así como muchos otros compañeros de la universidad) comenzaron a distribuirse el trabajo mediante grupos de comités. Así, por ejemplo, algunos compañeros se dirigieron al transporte público y mediante escritos relacionados con la educación y el movimiento estudiantil se dirigieron a los usuarios para crear consciencia de lo que estaba sucediendo y de lo que podría ocurrir si no se hacía algo al respecto. Otros compañeros, ya de la misma universidad, colocarían pancartas, alusiones y referencias entre la cultura popular y la crisis universitaria (Salazar, 2021a, 2021b).

Así también, se dirigieron a diferentes espacios públicos para continuar con la concientización de lo que estaba ocurriendo en la educación, el sistema educativo y el estado político del país. En este mismo sentido, ya que todas las universidades públicas de la nación buscaban una participación igualitaria e incluyente de los diferentes estamentos universitarios, se comenzaron a crear entidades como la Asociación Sindical de Profesores Universitarios, la Asociación Colombiana de Representantes Estudiantiles (ACREES) y Unión

2 La razón por la que Mariana Pajón se reunirá personalmente con Iván Duque, 4.10.2018.

https://www.pulzo.com/deportes/reunion-entre-mariana-pajon-presidente-ivan-duque-PP569140 
Cruz, J., \& Castillo, M. C. (2021). Estallido social, Covid-19 y educación: el caso del país que le tiene más miedo a un gobierno opresor que a un virus mortal Revista Convergencia Educativa, (10), diciembre, 78-90. https://doi.org/10.29035/rce.10.78

Nacional de Estudiantes de Educación Superior (UNEES), donde cada una tenía un vocero que recogía las conclusiones de las diferentes asambleas estudiantiles de cada universidad participativa.

Pero también fue un año bastante violento en cuanto a la dispersión de las masas organizadas en puntos de concentración una vez finalizadas las jornadas de movilización: el Escuadrón Móvil Antidisturbios (ESMAD), desde su fundación en 1999, utilizó un uso desproporcionado de la fuerza y en el 2018 no haría excepción alguna: varios miembros de este escuadrón, junto a algunos militantes de la Policía Nacional e, incluso, civiles, en conjunto realizaron varios rompimientos a los Derechos Humanos a lo largo de los dos meses. Así mismo, un estudiante de la Universidad del Cauca, Esteban Mosquera Iglesias, perdería uno de sus ojos debido a un funcionario del ESMAD, quien lanzó una granada de gas lacrimógeno al momento de dispersar (BBC News Mundo, 2020, González, 2018).

Pasarían dos meses antes de que el presidente comenzara a realizar mesas de diálogo con los estudiantes, y la vista que llegaba al final de las protestas de este año se encontraban todavía muy en el horizonte: los estudiantes pedían mayor presupuesto, mejor infraestructura, reformas a las reformas que tenían ahogadas a todas las instituciones de educación superior. El gobierno, por su parte, comenzaría a rechazar las demandas monetarias, inversión hacia algunos campus y cambios políticos. Sin embargo, justo antes de finalizar el año, los estudiantes y el gobierno de Iván Duque Márquez lograron llegar a acuerdos históricos para la educación: se concentraba en el mayor presupuesto en toda la historia educativa de Colombia, 4.5 billones de pesos adicionales para el presupuesto del próximo año

Así pues, con esa promesa por el entonces recién presidente Iván Duque Márquez, se llegaron a algunos acuerdos, muchos de ellos históricos (histórica, también, la cantidad de gente que apoyó movilizándose o demostrando estar a favor del Paro Nacional Estudiantil). Los estudiantes cumplimos y levantamos todo, esperando el cumplimiento por parte del Gobierno, celebrando, declarando históricos todos los acuerdos a los que se llegó. Ese año nos sentimos victoriosos, capaces, osados y, en cierta medida, invencibles. Ya el asunto sería recuperar el tiempo, con tres semestres en un año. Pero no importaba: si logramos algo con el Gobierno, lograríamos más con lo académico.

\section{La primavera colombiana}

Al año siguiente, en 2019, los estudiantes, terminando de recuperarnos de dos meses de paro, volvimos a parar porque casi todo lo que nos prometieron no fue cumplido: de los 4.5 billones adicionales, solo habían entregado 1.56 millones. También fue el año de aquel $21 \mathrm{~N}$, día que representaría todo el descontento nacional frente a la administración del Gobierno, pues no era más ni menos que toda la clase politiquera bélica que el pueblo deseaba arrancar del poder. Casi todos los sindicatos obedecieron a la huelga, hubo protestas en todos los rincones del país, la mayoría de las personas que no protestaron vivieron una especie de feriado; el país quedó paralizado por un día. Desde casi todos los sectores del país, se escuchaba la unión al paro en contra del paquetazo, exigiendo que se cumplieran los acuerdos convenidos el año pasado entorno a la educación, los asesinatos calculados y el proceso de paz. También, esa misma noche, salieron varios ciudadanos a continuar con el paro con la cacerola de la casa. Un primo mío también participó allí, y 
Cruz, J., \& Castillo, M. C. (2021). Estallido social, Covid-19 y educación: el caso del país que le tiene más miedo a un gobierno opresor que a un virus mortal Revista Convergencia Educativa, (10), diciembre, 78-90. https://doi.org/10.29035/rce.10.78

casi no me lo cuenta cuando regresó a la casa y su mujer vio el estado en que trajo la olla. "Pero qué importa la olla, si yo me debía manifestar. Eso se recupera, pero quién sabe si nos recuperemos de un paquetazo como ese", me decía (Silva, 2020).

El Gobierno, que de por sí no había agradado desde su posicionamiento en 2018 y que, de hecho, fue recibido a los pocos días con el Paro Nacional Estudiantil, venía demostrando cada vez más su deficiencia frente a temas políticos, sociales y económicos, así como su familiaridad y simpatía con la clase oligárquica colombiana, especialmente con la llamada Ñeñe política, donde en marzo de 2019, se denuncia el uso de dinero del narcotráfico para la compra de votos del posicionado presidente, salpicándolo a él, a la directora y muchos miembros del Centro Democrático e, incluso, al mismísimo Álvaro Uribe Vélez, ante lo que se negó toda relación con intereses políticos, atribuyendo el hecho a meras coincidencias de encuentros eventuales (Palma, 2019).

Aquí comenzaría también a sonar el grito de la olla a presión por la inconformidad con la Fuerza Pública representada por el Escuadrón Móvil Antidisturbios (ESMAD), desde aquel 23 de noviembre, donde sería impactado en su humanidad el joven estudiante de secundaria, Dilan Cruz con una escopeta calibre 12, llevándolo a su fallecimiento dos días después.

Internacionalmente comenzamos a llamar la atención, quizá porque al mismo tiempo estalló la revolución chilena y las manifestaciones en Argentina, también muy notorias, más todavía no habría ningún tipo de participación internacional en el tema del paro. Esta vez fue muy poco lo que se logró; si bien la educación recibió parte del dinero prometido, no significaba siquiera la mitad de lo acordado, el paquetazo se introdujo de todas formas y, cuando el Comité Nacional de Paro y el presidente Iván Duque se dispusieron a dialogar en marzo de 2020 para llegar a otros acuerdos y levantar el paro, llegó la pandemia. Con la pandemia, llega el aislamiento y, con el aislamiento, el paro llega a un punto muerto, caracterizado por el desánimo, y la falta de palabra por parte del Estado para sacar esto adelante ganó; pero se olvidaron de observar las cenizas de la fuerza quemada (Santana, 2019).

\section{La Gran Reclusión}

En 2020, las cenizas comenzaban a juntarse: aumento en el armamento bélico -aunque, hay que decirlo, este gasto fue a nivel mundial-, publicidad cuyo presupuesto fue tomado del Fondo de Programas Especiales para la Paz ${ }^{3}$ y ¿viajes ${ }^{4}{ }^{4}$, mientras en todo el país existía un aislamiento "preventivo" obligatorio. Y, sí, pongo "preventivo", pues el Gobierno de Iván Duque tardó alrededor de dos semanas desde que se conoció el

3 Se estima que el gobierno de Iván Duque Márquez gastó más de 20000 millones (más de USD 5000 000) solamente en su programa diario "Prevención y acción", de los cuales el 50\% habrían sido recogidos desde este Fondo, acto considerado sumamente inoportuno, teniendo en cuenta que el Fondo de Programas Especiales para la Paz está destinado al presupuesto que maneja el Acuerdo de Paz de 2016; acuerdo que el señor presidente y su partido político ha atacado fuertemente desde su anunciamiento.

4 El fiscal general Barbosa y el contralor general estuvieron en San Andrés Islas para reconocer el impacto de la pandemia en la isla. Sin embargo, llama la atención que sus esposas e hijos estuvieron con ellos durante el viaje. Así mismo, ese mismo año, el presidente Iván Duque utilizó el avión presidencial para llevar a su esposa e hija y las amigas de ellas (junto a sus madres), a una hacienda en el centro-oeste del país. Pero esto lo validó la presidencia, con el argumento de velar por la «seguridad de la familia presidencial». 
Cruz, J., \& Castillo, M. C. (2021). Estallido social, Covid-19 y educación: el caso del país que le tiene más miedo a un gobierno opresor que a un virus mortal Revista Convergencia Educativa, (10), diciembre, 78-90. https://doi.org/10.29035/rce.10.78

paciente cero en Colombia, hasta que nos encerraron a todos. E, igualmente, el aeropuerto -teniendo en cuenta que el paciente cero llegó desde Italia- continuaba su uso ordinario, sin ningún tipo de mediación. Para este mismo tiempo, la Fiscalía General de la Nación también comenzaría a realizar investigaciones con la Ñeñe política, lo que implicaría la renuncia de muchas personas del Centro Democrático. Pero, a fin de cuentas, como era de esperarse, las investigaciones no llegaron a ningún resultado, aunque el caso continuaba abierto (BBC News Mundo, 2021).

Finalmente, llegaría aquello que despertaría las brasas y al fénix para comenzar a volar: ese mismo año, dos agentes de la policía civil redujeron hasta la muerte al estudiante, padre y taxista Javier Ordoñez. Tras conocer este lamentable incidente, estallaron -principalmente en Bogotá- una serie de protestas contra la brutalidad policial. En la noche del 11 de septiembre, 10 personas murieron y 315 resultaron heridas (más de 70 personas heridas fueron a bala) en la capital del país.

En otras ciudades del país, también hubo protestas contra los abusos policiales y se rechazó categóricamente el caso de Ordóñez, la mayoría de los cuales terminaron en enfrentamientos entre uniformados y manifestantes. Esto fue lo que hizo a la ciudadanía regresar a las calles, a manifestarse, a indignarse, a protestar. Hasta el 2019, el ESMAD que respondió solo con gases lacrimógenos, ahora comenzaría a "dispersar" con armas de fuego a civiles desarmados. A partir de aquí, pienso yo, fue que la ciudadanía comenzó a tenerle más rabia al Gobierno, que miedo a la pandemia. Los picos continuaban creciendo, las personas no tenían trabajo, comida, ni salud; la gente seguía muriendo y el Gobierno continuaba... haciendo lo que sea que el Gobierno estaba haciendo. Finalmente, para finales de junio comenzaría la reactivación económica, lo que implicaría diferentes medidas de bioseguridad que fueron aplicando poco a poco en diferentes lugares, hasta que en 2021 se volvió la denominada Nueva normalidad.

\section{A parar para avanzar...}

La situación económica para inicios de este año no era muy favorable: el año pasado dejó a las empresas, los bancos y el mismo Estado, endeudados hasta el cuello. Incluso el PIB llegó a su punto más bajo y catastrófico en los últimos cuarenta años. Por ende, se necesitaba recolectar veintitrés mil billones de pesos para poder dar abasto con, al menos, las deudas que dejó el estado de alerta por la pandemia. Sin embargo, y como afirma Salazar (2021b), en lugar de buscar recolectarlos mediante las entidades de mayor capacidad económica, el Gobierno estaba destinando la cosecha mediante la población vulnerable de la nación, lo que implicaría implementar impuestos a la canasta familiar, aumentar el precio de la gasolina, los peajes, el transporte público, eliminar la categoría de bienes exentos de IVA, mientras se aumenta la cobertura de la devolución del impuesto; aumentar la base gravable del impuesto de renta para personas naturales; volver permanente el impuesto al patrimonio; crear impuestos verdes, eliminar una devolución monetaria por parte del Estado al campesino (lo que aumentaría el precio de todos los alimentos), buscaba realizar las 
Cruz, J., \& Castillo, M. C. (2021). Estallido social, Covid-19 y educación: el caso del país que le tiene más miedo a un gobierno opresor que a un virus mortal Revista Convergencia Educativa, (10), diciembre, 78-90. https://doi.org/10.29035/rce.10.78

reformas (de educación, pensionales y laborales) que en anteriores años no había logrado y aumento al IVA de los productos de consumo básico (agua, luz, gas) a la clase media y media baja. ${ }^{5}$

Es decir, todo sitio donde prima el dinero quedaba exenta de ayudar con la deuda del Estado, y nosotros, los pobres, los nadie, debíamos acarrear con todo el alto costo, cuando, incluso, la mayoría de esta población debe estar hasta en tres trabajos para poder sobrevivir en este país. Añado el malestar generado por la demora con el plan de vacunación nacional del cual solo se sabía que habían llegado cincuenta mil dosis de vacunas a inicios de febrero, pero no había ningún anuncio de plan de vacunación. Toda esta mal llamada Ley de Solidaridad Sostenible fue presentada a inicios de abril y se pensaba aplicar una vez pasada Semana Santa (Palomino, 2021, Publimetro Colombia, 2018).

Con lo que no contaría nadie del Gobierno es que, aún en pandemia y con leves noticias de inicio de jornadas de vacunación para los mayores de edad, el pueblo colombiano, en su totalidad, se reuniría el veintiocho de abril a rechazar la Reforma Tributaria. Así, entonces, ese 28A comenzó el Paro Nacional de este año que, considero, es más una reactivación del 2019 - recordando que fue frenado debido al inicio de la pandemia, sin haber llegado a ningún acuerdo-, trayendo consigo la ahora costumbre de convocar con el día seleccionado y la inicial del mes acordado para la manifestación (Bermúdez, 2021, Redacción Vivir, 2018, Redacción Bogotá, 2020).

De cierta manera, es como si tres años de este gobierno pudieran resumirse en los últimos tres meses de Paro Nacional en Cali: desconformidades, injusticias, abandono, asesinatos, desapariciones, incumplimientos, creación de la Primera Línea (también a nivel social, cultural y jurídica), despedidas, renuncias, asignación de embajadas, burlas a la población mediante toma de decisiones ${ }^{6}$, entre otros.

Ahora, bien, cabe mencionar que el mandato de Iván Duque Márquez ha realizado algo que nunca, en la historia de Colombia, había sucedido: dividió a toda el ala derecha del poder. Incluso, dentro de su mismo partido, el Centro Democrático, se estaban disputando acerca de si Duque debía venir a Cali para hablar con los manifestantes, entablar diálogos y plantar soluciones con la creciente crisis que estaba generando el paro, o buscar otros métodos menos diplomáticos. Esto se expandió en toda el ala derecha de la política tradicional, al punto de que ahora, el mismo que colocó a Iván Duque Márquez en el poder, el exsenador Álvaro Uribe Vélez, haya anunciado no apoyar a ningún precandidato presidencial. Esto llama la atención, especialmente porque entre esos precandidatos, hasta hace poco, sonaba su propio hijo, Tomás Uribe Moreno (Blandón, 2018).

5 Esto forma parte de un artículo elaborado por Carolina Salazar Sierra para la revista especializada en economía La República (2021b), donde analiza las reformas que se han realizado en Colombia desde el año 1897, hasta la última aceptada en el 2019, siendo en total 50 reformas tributarias, de las cuales 12 fueron implementadas desde el expresidente Álvaro Uribe Vélez, hace 19 años, donde comenzarían las sobretasas a los impuestos y la implementación de nuevos impuestos.

6 Tras la renuncia de Carolina Soto como directora del Banco de la República, atribuido a la confirmación de su esposo Alejandro Gaviria como candidato presidencial, el presidente Iván Duque Márquez nombró codirector a Alberto Carrasquilla, quien renunciara a su cargo luego de haber sido rechazada la Reforma Tributaria en el Senado. 
Cruz, J., \& Castillo, M. C. (2021). Estallido social, Covid-19 y educación: el caso del país que le tiene más miedo a un gobierno opresor que a un virus mortal Revista Convergencia Educativa, (10), diciembre, 78-90. https://doi.org/10.29035/rce.10.78

La pandemia se agravaría, pero todos estuvimos de acuerdo en que eso se superaría, pero ¿cómo se recupera uno de una deuda eterna con el Estado? Si todo impuesto que realizan como de emergencia, se vuelve ley y la aumentan. Esta vez, la voz la levantamos tan fuerte que llegó a diferentes instancias de Derechos Humanos, lo que incluso traería la visita de la Comisión Interamericana de Derechos Humanos para revisar las denuncias. Como se esperaba, la Comisión estuvo a favor de los Derechos Humanos, aconsejándole al Gobierno que respetara todo lo involucrado a los mismos. Pero, claro, si los consejos fueran obligatorios e inmediatos, ni libros de autoayuda se escribirían ya. También se manifestaron políticos, intelectuales e, incluso, artistas del entretenimiento -aunque fueron muy pocos los locales.

A nivel internacional, llegaría la prensa norteamericana, francesa y alemana. Particularmente, de la alemana, se volvería notoria una periodista, quien se quedó por su voluntad, mientras participaba activamente en el Paro Nacional en Cali. También llegaría la Comisión Interamericana de Derechos Humanos, con sede en Washington D.C., pero, si de algo sirviesen las recomendaciones y solicitudes, los libros de autoayuda sí serían obsoletos (Pardo, 2019, González, 2019).

Finalmente, no sería el presidente quien hablara con los protestantes, en su mayoría jóvenes buscando oportunidades, sino que serían los mismos alcaldes con quienes llegarían a un acuerdo. Particularmente en Cali, el alcalde Jorge Iván Ospina llegó a los acuerdos que los jóvenes buscaban: oportunidades laborales, soporte económico, auxilio estatal. Ya luego, la clase alta de la ciudad (y de gran parte del país) lo tacharía de vándalo, de hijo de guerrillero, de buscador de beneficios mediante la destrucción de la ciudad, y mil cosas más. Buscan ahora también su renuncia, su sacada de la Alcaldía, pero, a diferencia de otros alcaldes de capitales, considero que hizo lo mejor: escuchar al pueblo y llegar a algo. No es que yo apoye al alcalde, particularmente no apoyo a ningún político, pero siempre estaré de acuerdo con que se escuche al inconforme, al marginado, al que alza la voz porque nadie le escucha.

\section{A manera de conclusión}

He visibilizado, pues, las condiciones que fueron propicias para la culminación del estallido social que Colombia lleva viviendo los últimos cinco meses del presente año. No se trata únicamente de una falta de responsabilidad social del actual gobierno colombiano, sino que esto corresponde a un malestar civil que decidió actuar, gritar y molestar cuando no fue escuchado mientras negociaba, hablaba y estaba en una tensa calma. Se puede ver que, si bien el presidente comenzó su mandato con negociaciones con la ciudadanía, siento que eso debió estar relacionado a su recién posicionamiento como presidente de Colombia. Del 2019 en adelante, vemos que cada vez fueron menos las participaciones de la ciudadanía que se manifestaba en contra de los planes del gobierno.

Ahora bien, me es difícil dar una especie de conclusión respecto a esta situación de las manifestaciones -no así del ensayo-, pues el Paro Nacional no ha terminado, mas sí está pausado en Cali. En Bogotá, Barranquilla, Popayán, Medellín y muchas otras ciudades, se sigue matando, desapareciendo, gritando, luchando. Aunque Cali dio muchas vidas por un mejor país, realmente, después de todo lo sucedido, queda una indiscutible sensación de derrota. No puedo decir que la Reforma Tributaria ahora sí tiene más sentido, 
Cruz, J., \& Castillo, M. C. (2021). Estallido social, Covid-19 y educación: el caso del país que le tiene más miedo a un gobierno opresor que a un virus mortal Revista Convergencia Educativa, (10), diciembre, 78-90. https://doi.org/10.29035/rce.10.78

pues fue aprobada mientras dormíamos y ni siquiera se compartió con el pueblo. Aun así, pienso que hay cosas positivas: la especial atención que comenzamos a darle a los medios alternativos de información; las revistas alternativas y populares que surgieron gracias al paro desde 2019; movimientos políticos y sociales que germinaron a partir del estallido social; el que tumbaran la reforma tributaria cuando fue presentada por primera vez, la renuncia de Alberto Carrasquilla como ministro de hacienda, la autorregulación de la sociedad (como, por ejemplo, en Cali la misma ciudadanía construyó un Monumento a la Resistencia), la resistencia que ha tenido el pueblo que sigue luchando y creyendo, la organización civil mediante, la autorregulación, así como la participación desde lo local: vecindario, barrio, comuna, ciudad. Pienso, entonces, que esto es solo el comienzo de algo más grande, más importante, más certero. Sin embargo, de momento, solo puedo asegurar que nos hemos dado cuenta de que don Iván no es el presidente de Colombia, sino el amigo de la alta politiquería, el presidente de la clase alta y alto jefe de todos los demás. Pero solo le queda un año, la política tradicional ha quedado bastante herida y los jóvenes ahora están más interesados en estos temas. Si ha habido un verdadero cambio posible en los últimos treinta años para Colombia, es el que estamos viviendo. 
Cruz, J., \& Castillo, M. C. (2021). Estallido social, Covid-19 y educación: el caso del país que le tiene más miedo a un gobierno opresor que a un virus mortal Revista Convergencia Educativa, (10), diciembre, 78-90. https://doi.org/10.29035/rce.10.78

\section{REFERENCIAS BIBLIOGRÁFICAS}

BBC News Mundo (10 de septiembre de 2020). Javier Ordoñez: 10 muertos y decenas de heridos en Colombia durante las protestas por la violencia policial. $B B C$ News Mundo. https://www.bbc.com/mundo/noticias-america-latina-54106609

BBC News Mundo (29 de abril de 2021). 3 factores para entender las protestas en Colombia y la indignación contra la reforma tributaria. BBC News Mundo. https://www.bbc.com/mundo/noticias-americalatina-56932013

Bermúdez, G. (06 de septiembre de 2021). Postales de un viaje al corazón del Paro Nacional en Cali. Cuestión Pública. https://cuestionpublica.com/postales-de-un-viaje-al-corazon-del-paro-nacional-en-cali/

Blandón, D. (11 de octubre de 2018). Tras marcha estudiantil, inicia paro nacional de universidades públicas. NotiCentro 1 CM\&. https://noticias.canal1.com.co/nacional/tras-marcha-estudiantilinicia-paro-nacional-de-universidades-publicas/

Forbes Staff. (27 de agosto de 2020). Más de $\$ 20.000$ millones ha gastado el Gobierno en publicidad oficial. Forbes Colombia. https://forbes.co/2020/08/27/actualidad/mas-de-20-000-millones-hagastado-el-gobierno-en-publicidad-oficial/

González, L. (12 de octubre de 2018). Estudiantes de universidades públicas de Colombia declaran paro indefinido por presupuesto. Sputnik Mundo. https://mundo.sputniknews.com/20181012/crisiseducacion-superior-colombia-1082666875.html

González, L. (21 de noviembre de 2019). Bogotá se sumerge en protestas y en un paro nacional. Sputnik Mundo. https://mundo.sputniknews.com/2091121/21n-bogota-se-sumerge-en-protestas-y-enun-paro-nacional-1089394841.html

Moreno, O. (2018). La financiación de la ed. sup. y las deudas de los estudiantes. El Observatorio de la Universidad Colombiana. https://www.universidad.edu.co/la-financiacion-de-la-ed-sup-y-lasdeudas-de-los-estudiantes-oscar-moreno-nov-18/

Palomino, S. (30 de junio de 2021). Paro nacional 2021, un hito en la protesta social de Colombia. Anadolu Agency. https://www.aa.com.tr/es/an\%C3\%A1lisis/paro-nacional-2021-un-hito-en-la-protestasocial-de-colombia/2290453

Palma, E. (26 de noviembre de 2019). La primavera colombiana. Las 2 Orillas. https://www.las2orillas.co/la-primavera-colombiana/

Pardo, D. (22 de noviembre de 2019). Paro nacional en Colombia: 3 factores inéditos que hicieron del 21 de noviembre un día histórico. BBC News Mundo. https://www.bbc.com/mundo/noticias-americalatina-50520302 
Cruz, J., \& Castillo, M. C. (2021). Estallido social, Covid-19 y educación: el caso del país que le tiene más miedo a un gobierno opresor que a un virus mortal Revista Convergencia Educativa, (10), diciembre, 78-90. https://doi.org/10.29035/rce.10.78

Publimetro Colombia (14 de diciembre de 2018). Esto fue lo que lograron los estudiantes con el paro de dos meses. Publimetro. https://www.publimetro.co/co/noticias/2018/12/14/fue-lo-lograron-losestudiantes-paro-dos-meses.html

Pulzo (4 de octubre de 2018). La razón por la que Mariana Pajón se reunirá personalmente con Iván Duque. Pulzo. https://www.pulzo.com/deportes/reunion-entre-mariana-pajon-presidente-ivan-duque$\underline{\mathrm{PP} 569140}$

Redacción Bogotá (10 de septiembre de 2020) Cinco muertos, 80 heridos y CAI incendiados: balance de protestas por abuso policial. El Espectador. https://www.elespectador.com/bogota/cincomuertos-80-heridos-y-cai-incendiados-balance-de-protestas-por-abuso-policial-article/

Redacción Vivir (16 de noviembre de 2018). Un mes de marchas universitarias en 12 claves. El Espectador. https://www.elespectador.com/educacion/un-mes-de-marchas-universitarias-en-12-clavesarticle-823790/

Salazar, C. (16 de febrero de 2021a). La caída de 6,8\% del Producto Interno Bruto de 2020 fue la peor de la historia del país. La República. https://www.larepublica.co/economia/la-caida-de-68-delproducto-interno-bruto-de-2020-fue-la-peor-de-la-historia-del-pais-3125632

Salazar, C. (01 de abril de 2021b). En Colombia se han hecho más de 50 reformas tributarias desde 1897. La República. https://www.larepublica.co/especiales/mis-documentos-semana-santa-2021/encolombia-se-han-hecho-mas-de-50-reformas-al-sistema-tributario-en-mas-de-un-siglo-3147619

Santana, P. (14 de noviembre de 2019) El paro nacional del 21 de noviembre. América Latina en movimiento. https://www.alainet.org/es/articulo/203245

Silva, D. (11 de septiembre de 2020). 13 civiles muertos y más de 400 heridos en dos días de protestas en Colombia por la muerte de Javier Ordóñez. CNN en español. https://cnnespanol.cnn.com/2020/09/11/10-civiles-muertos-y-mas-de-400-heridos-en-dosdias-de-protestas-en-colombia-por-la-muerte-de-javier-ordonez/ 
Cruz, J., \& Castillo, M. C. (2021). Estallido social, Covid-19 y educación: el caso del país que le tiene más miedo a un gobierno opresor que a un virus mortal Revista Convergencia Educativa, (10), diciembre, 78-90. https://doi.org/10.29035/rce.10.78

\section{Datos de correspondencia}

María Camila Castillo Cabezas

Magíster en Educación

Universidad del Valle

Cali, Colombia.

Dirección postal: 76001

ORCID: https://orcid.org/0000-0003-4086-9686

Email: maria.castillo.cabezas@correounivalle.edu.co 